\title{
Dengue: ações de combate aos vetores
}

Dengue: actions to fight vectors

Coordenadoria de Controle de Doenças (CCD).

Superintendência de Controle de Endemias (Sucen)

Desde 1997, 11 municípios no Estado de São Paulo apresentam transmissão da dengue todos os anos. Entre eles destacam-se aqueles que facilitam a difusão da dengue dentro do Estado, devido ao grande fluxo de turistas provenientes de todas as regiões do Estado e do País. Foram notificados 4.665 casos autóctones de dengue (até a semana epidemiológica 32) no Estado de São Paulo, em 2005, cerca de 50\% acima do registrado no ano de 2004 (3.060 casos autóctones).

Em 2004, três regiões foram responsáveis por 80,4\% dos casos autóctones de dengue no Estado: Baixada Santista, com 1.374 casos (45,1\%); Litoral Norte, com 517 casos (17,0\%); e Vale do Paraíba, especificamente o município de Potim, com 558 casos $(18,3 \%)$. Em 2005, a Baixada Santista continuou se destacando com relação à transmissão de dengue, apresentando, no mesmo período, 1.825 casos autóctones, $39,1 \%$ do total do Estado. Além desta região, os municípios de Olímpia, Ribeirão Preto e São José do Rio Preto também se destacaram no período citado com respectivamente, 834 $(17,6 \%), 478(10,2 \%)$ e 238 casos $(5,1 \%)$.

A região da Baixada Santista reveste-se de grande importância epidemiológica na transmissão de dengue, por apresentar complexo conglomerado urbano, com inúmeras áreas sem estrutura urbana adequada, elevada densidade, importante movi- mentação populacional e grande número de imóveis fechados (temporada). Além disso, apresenta condições climáticas extremamente favoráveis ao desenvolvimento do vetor (temperatura e umidade). A cidade de Santos possui o maior porto da América Latina, com 15 hectares e 18 quilômetros de extensão, que movimenta 41 milhões de toneladas e 700 mil contêineres por ano, em 4.000 navios que atracam no cais, sendo responsável por $25,4 \%$ do comércio externo do País.

De 1997, início da transmissão de dengue nessa região, até junho de 2005, o número de casos autóctones de dengue na Baixada (66.682) corresponde a $43,7 \%$ do total de casos autóctones do Estado (152.417).

Em relação à situação entomológica, o programa de controle baseia-se na redução das populações de Aedes aegypti. Atualmente, essa espécie está distribuída por 498 municípios paulistas $(77,2 \%)$, onde vivem, aproximadamente, $85 \%$ da população do Estado. Desses municípios infestados, cerca de $60 \%$ já tiveram registro de casos autóctones de dengue.

As atividades vetoriais são diferenciadas, segundo a infestação. Nas regiões onde a espécie não está estabelecida, as ações voltam-se à vigilância, visando a evitar a dispersão da espécie, mediante atividades programadas. Nas regiões infestadas

Tabela 1 - Número de imóveis trabalhados na atividade casa a casa, segundo equipe e mês. Estado de São Paulo. Janeiro a maio de 2005.

\begin{tabular}{lcccccc}
\hline M ês & Jan & Fev & M ar & Abr & M ai & Total \\
\hline Equipe & & & & & & \\
$\quad$ Controle de vetores & 640.103 & 701.626 & 758.570 & 615.355 & 692.352 & 3.408 .006 \\
PACS/PSF & 120.254 & 124.659 & 188.921 & 180.164 & 202.391 & 816.389 \\
\hline Total & 760.357 & 826.285 & 947.491 & 795.519 & 894.743 & 4.224 .395 \\
\hline
\end{tabular}

PACS: Programa de Agente Comunitário de Saúde

PSF: programa de Saúde da Família

Correspondência/Correspondence: $\quad$ *Texto de difusão técnico-científica da Secretaria de Estado da Saúde de São Paulo.

Secretaria de Estado da Saúde de São Paulo

Av. Dr. Arnaldo, $3511^{\circ}$ andar sala 135

01246-901 São Paulo, SP, Brasil

E-mail: agencia@saude.sp.gov.br 
Tabela 2 - Número de imóveis trabalhados em período de transmissão, segundo atividade e mês. Janeiro a maio de 2005.

\begin{tabular}{lcccccc}
\hline Atividade/mês & Jan & Fev & M ar & Abr & Mai & Total \\
\hline Controle de Criadouros 101.612 & 134.902 & 164.694 & 204.725 & 197.028 \\
Nebulização & 8.404 & 22.389 & 37.833 & 54.486 & 802.961 \\
\hline
\end{tabular}

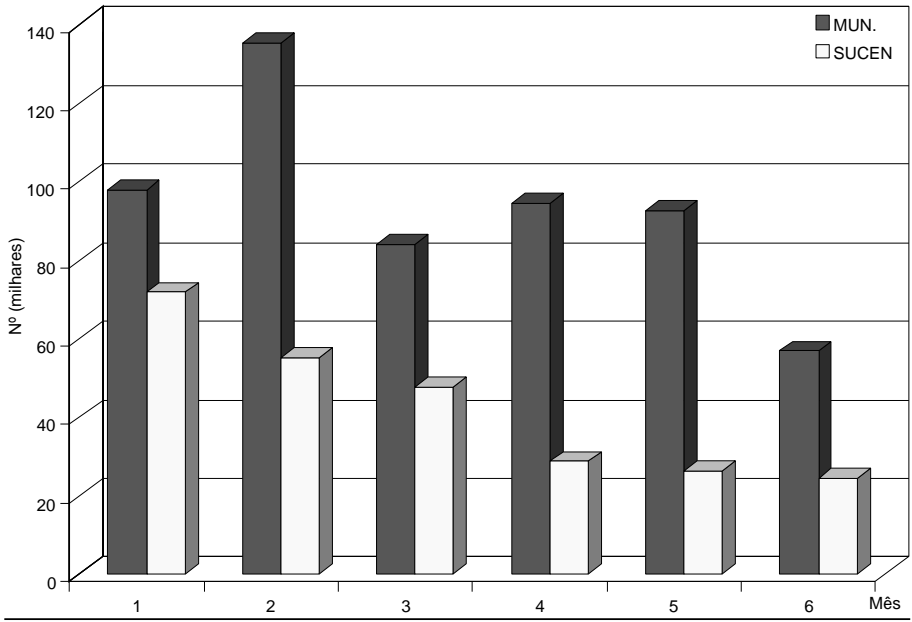

Figura 1 - Número de imóveis trabalhados em Avaliação de Densidade Larvária, por mês. Estado de São Paulo, 2005.

são realizadas atividades de rotina para controle vetorial: visitas casa a casa e em imóveis especiais e pesquisa/tratamento químico em pontos estratégicos. De janeiro a maio de 2005, mais de 4 milhões de imóveis em áreas infestadas por Aedes aegypti foram trabalhados na visita casa a casa. Essa atividade foi realizada por equipes municipais de controle de vetores e dos programas de Agente Comunitário de Saúde (PACS) e da Saúde da Família (PSF) (Tabela 1).

Outras atividades de controle são desencadeadas quando ocorre transmissão: bloqueio-controle de criadouros e bloqueio-nebulização (Tabela 2).

Nas regiões infestadas realiza-se também a vigilância vetorial, mediante a determinação dos níveis de infestação, por meio da Avaliação de Densidade Larvária. O indicador adotado no programa é o Índice de Breteau (IB). A Figura mostra, comparati- vamente o número de imóveis trabalhados nesta atividade em todo o Estado, em 2005 pelas equipes municipais e da $\mathrm{Su}-$ perintendência de Controle de Endemias (Sucen).

Historicamente, os níveis de infestação do vetor no Estado mostram sazonalidade bem demarcada, registrando valores altos no verão e reduzidos a níveis próximos de zero, no inverno. Observa-se na Tabela 3 que no primeiro trimestre de 2005 , para a maioria dos municípios, o valor estimado para o IB foi superior a 5,0, sendo que em considerável número desses municípios este valor foi superior a 10,0. Estes dados apontam para um agravamento da situação epidemiológica e, portanto, reforçam a necessidade da manutenção das atividades preconizadas no Programa de Controle de Dengue.

Destaca-se que das 40 avaliações realizadas entre abril e junho, meses menos favoráveis à proliferação do vetor, 26 (65\%) resultaram em IB maior que 2,0 .

Nos últimos anos ocorreram invernos atípicos, com temperaturas mais elevadas e índices pluviométricos acima da média. Portanto, é alto o risco de ocorrer transmissão importante nos próximos meses, pois o período mais propício ao desenvolvimento do vetor se iniciará com níveis de infestação acima do esperado.

Em vista do exposto, é fundamental o envolvimento de todos os segmentos da sociedade, na busca de melhores perspectivas de controle de dengue.

Tabela 3 - Níveis de infestação por Aedes aegypti segundo Avaliação de Densidade Larvária (IB*). Estado de São Paulo. Janeiro a junho de 2005 .

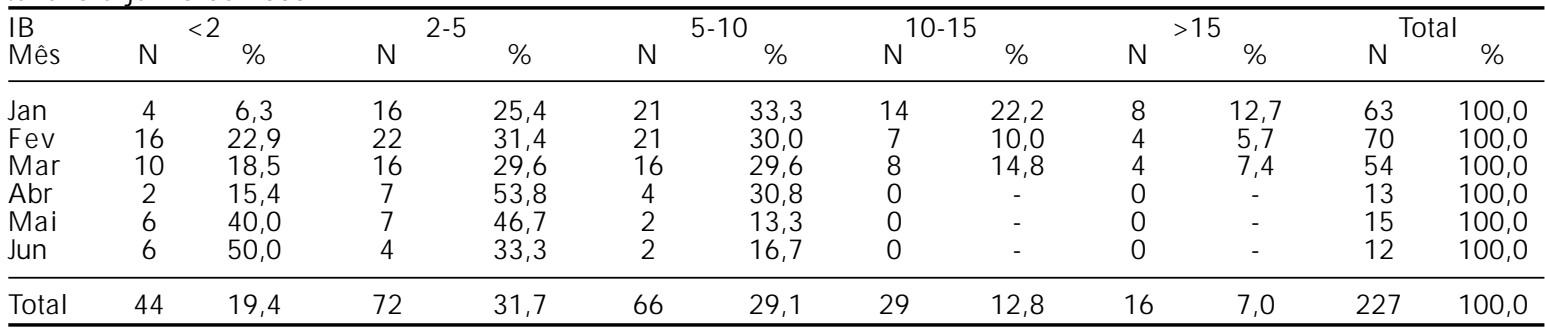

*IB: Índice de Breteau

Fonte: Superintendência de Controle de Endemias (Sucen), 2005 